\title{
Feasibility Analysis of PPP Mode in Rural Household Garbage Disposal -- Based on the empirical analysis of regional differences
}

\author{
Ruijiao Liu \\ Beijing Jiaotong University, China \\ 17120519@bjtu.edu.cn
}

Keywords: Rural garbage disposal, PPP Mode, Regional difference.

\begin{abstract}
This paper adopts a questionnaire survey method to obtain micro-data, summarizes the differences in the way households deal with household garbage in three different regions, establishes a binary logistic model, and empirically analyzes the influencing factors that affect the treatment effect of domestic garbage. There are significant gaps in the factors, economic development level, and historical and cultural differences between China's rural areas. Therefore, there will be differences in the provision of rural public goods. This paper proposes to apply the PPP model to the practice of rural garbage disposal to create a kind of Suitable for rural household garbage disposal mode.
\end{abstract}

\section{Introduction}

In 2015, the Central Document No.1 emphasized that we must comprehensively promote the improvement of rural human settlements, and guide and encourage the investment of social capital in rural construction. At present, China has a large stock demand in rural areas, and rural public goods will undoubtedly become the core of rural consumer demand. Domestic garbage disposal services, as a kind of rural public goods, can meet the public needs of rural society such as production and living.

In recent years, the amount of domestic garbage in rural China has increased rapidly, and the difficulty of treatment has increased[1]. Some local governments have established some fixed-point collection facilities for rural household garbage, such as trash cans and garbage stations. However, the problem of rural domestic garbage has still not been effectively solved. From the perspective of farmers, this paper reveals the reasons that are difficult to solve in the rural household rubbish problem, analyzes the existing difficulties and effectiveness of the existing rural household garbage disposal model, and applies the PPP mode to solve the problem. On the one hand, it is conducive to the improvement of existing methods for the treatment of rural domestic waste. Based on continuous innovation and improvement, we will select a waste disposal model that is suitable for the region. On the other hand, it is beneficial to provide operative guidance for the treatment of rural domestic garbage in China.

\section{Theoretical analysis}

\subsection{Model selection}

At present, the mode of rural household garbage disposal is generally that the households put the garbage into the designated locations of the village, and then the villages collect them in a unified manner and concentrate on the treatment. This paper adopts a questionnaire survey method to investigate the behavior of household households in the treatment of rural household waste and the effect of domestic garbage collection. In fact in some areas, even if village provide household garbage collection facilities in villages, some rural households still use non-point dumping methods to discard household garbage at will, seriously affecting village environmental sanitation and governance[2]. Farmers are " natural person " and " rational man ". Different environments will affect the behaviors of farmers. In the following, the factors influencing the behavior of rural 
households will be described in terms of their own characteristics, household characteristics, public product supply, and social environmental public opinion.

Here is a study of the ways in which households dump domestic waste. It is divided into designated dumping and non-point dumping. It is a typical two-category variable. The value assigned to the farmer when the designated point is dumped is 1 and the value is 0 when the point is not fixed. It is advisable to use the binary Logistic probability distribution function to perform empirical subdivision. The specific function expression is as follows:

$$
\mathrm{Y}_{\mathrm{t}}=\alpha+\sum \beta_{\mathrm{i}} \mathrm{X}_{\mathrm{i}}+\varepsilon_{\mathrm{i}} \quad \mathrm{i}=1,2, \ldots, \mathrm{n}
$$

Where $\alpha$ is a constant term, $\beta_{\mathrm{i}}$ is a regression coefficient, $\mathrm{X}_{\mathrm{i}}$ is a set of explanatory variables affecting the behavior of the farmer, and $\varepsilon_{\mathrm{i}}$ is a random disturbance term.

\subsection{Variable selection}

In order to verify the research hypothesis proposed in the previous article and based on the availability of empirical research, we propose the following research variables: (1) Set the farmer's own characteristics as the farmer's gender, age, education level and occupation; (2) Set the household characteristics as the number of resident population, living and consumption expenditures, agricultural production income and daily vegetable sources, waste treatment fees, households' disposal of garbage expenses and household daily garbage volume; (3) Household garbage collection in the village Where the public product supply is set to whether the village has a garbage collection point, whether the village has a hardened road, the distance to the nearest garbage collection point, and whether the village has special garbage cleaning personnel and garbage collection point clean-up status; (4) The social environment public opinion is set to whether it has received environmental education, status assessment of domestic garbage disposal, evaluation of farmers' responsibility and other people's views on your litter.

\section{Empirical analysis}

This data comes from May to October 2016 in Dongchangfu District, Liaocheng City, Shandong Province, Wuhu County, Anhui Province, and Wulong County, Chongqing City. The three counties selected 26 villages. After removing invalid samples, 430 valid questionnaires were finally obtained. Among them, there are 183 in Dongchangfu District, 126 in Penghu County and 121 in Wulong County.

Based on the model and variables described above, the final output results are shown in Table 1.

In terms of factors affecting the behavior of rural households, Dongchangfu District is mainly concerned with environmental public pressure and farmers' perception. Wulong County in Wuhu County in central China is mainly supplied with public goods, and Wuhu County in central China is affected by the above two factors. This shows that in addition to the internal factors such as their own endowments and family characteristics, which influence the choice of household garbage disposal methods, the level of economic and social development also plays an important role in the entire waste disposal process.

$77.6 \%$ of the farmers in Dongchangfu District paid the fee of 20 yuan per person per year to the village where they live. In Wulong County, only $27.3 \%$ of households in the village where the farmers lived pay for the disposal of household garbage, but the difference in fees is relatively large. Each household ranges from 10 to 120 and is charged by the village committee. The higher level government does not have unified charging rules. Only $10.3 \%$ of Wuhu County paid a small amount of fees to villages, up to a maximum of 20 yuan, to pay for village cleaning staff, and $89.7 \%$ of households did not pay fees to their villages. The villages in the three counties have large differences in their toll collection areas and have a certain relationship with the local economic development 
Table 1. Model estimation results of influencing factors

\begin{tabular}{|c|c|c|c|}
\hline Don & u District & Wuhu County & Wulong County \\
\hline \multicolumn{4}{|l|}{ Gender } \\
\hline Age & & $0.088 * * *$ & $0.135 * *$ \\
\hline Education level & & $1.477 * * *$ & \\
\hline \multicolumn{4}{|l|}{ Farming } \\
\hline \multicolumn{4}{|l|}{ Agricultural workers } \\
\hline \multicolumn{4}{|l|}{ Individual/Business } \\
\hline Resident population & & $-1.034 * * *$ & \\
\hline Consumer spending & & & $0.000 *$ \\
\hline Agricultural production income & $0.000 * *$ & & $0.000 * *$ \\
\hline Daily vegetable source & & & $-3.224 * *$ \\
\hline Pay the waste disposal fee & & & $0.143 * * *$ \\
\hline Household waste disposal expenses & & $0.015^{*}$ & \\
\hline Household daily garbage volume & & $1.328 * * *$ & $1.891 * *$ \\
\hline Does the village have garbage collection points? & & & $5.737 * * *$ \\
\hline \multicolumn{4}{|l|}{ Does the village have hardened roads? } \\
\hline Recent garbage collection point distance & $-1.544 * * *$ & & \\
\hline \multicolumn{4}{|l|}{ Is there a dedicated garbage cleaning staff in the village } \\
\hline Garbage collection point cleaning status & $-0.723 * * *$ & $-2.695 * * *$ & \\
\hline Is it environmentally friendly? & & $1.523 * *$ & \\
\hline Domestic waste treatment status assessment & $-0.847 *$ & & \\
\hline Evaluation of responsibility for farmers & & $3.678 * *$ & \\
\hline Other people's views on your litter & $-1.412 * * *$ & & \\
\hline Constant & 29.244 & -8.477 & -12.796 \\
\hline
\end{tabular}

Note: $* * *$, and $* * *$ indicate the significance levels of $10 \%, 5 \%$, and $1 \%$, and the space is not significant.

level. It also shows that the local government needs to improve the system of environmental governance.

According to Wulong County's data, the higher the fees paid by farmers, the more they tend to dump at designated sites. There are two main reasons: on the one hand, villages with high fees are more likely to be better at this job because of the protection of funds. Site dumping provides good infrastructure. On the other hand, peasant households' payment is equivalent to the service of purchasing villages to collect and clean up domestic garbage. The more fees a peasant household pays, the more it can promote its exercise of its due rights.

The sources of rural household garbage disposal funds can be governments, villagers' autonomous organizations, enterprises, and villagers. Difficulties in fundraising and single funding channels are currently the major bottlenecks in rural household garbage disposal funds in China[3]. The main reason for this is that the investment income of rural household waste treatment itself is low. Private capital for the purpose of profit is rarely involved in the governance of some rural environmental infrastructure. The essence of the PPP model is to achieve effective supply of environmental public goods through cooperation between the government and the private sector. The public sector relies on the private sector to improve the supply efficiency of environmental public goods[4]. The private sector uses the public sector to reduce operational risks. Through cooperation, both parties share revenue and share responsibility. This paper believes that the introduction of PPP model is very necessary and feasible.

At present, the treatment of rural household garbage is facing problems such as inadequate supply of facilities, shortage of funds, and lack of environmental awareness among farmers. As a public product category, rural household waste disposal should be the government[5]. However, due to the lack of financial resources, the grass-roots government has caused a serious shortage of funds in this area. Under the PPP model, through the introduction of market competition mechanisms and advanced management models in rural garbage disposal projects, government agencies can reflect on 
the inadequacies of the traditional model in the process of cooperation, and promote the transformation of government functions and efficiency[6]. At the same time, the government has changed from the provider of waste treatment services to the purchaser and supervisor, allowing it to emerge from the operations of waste disposal projects, focusing on the supervision and assessment of water pollution treatment projects, and improving the efficiency of the government.

\section{Summary}

The government, as the most important supply subject, has to transform its functions from "power type" to "service type", and must play a leading role in the supply of rural public goods to make up for market failures. The market as a basic mechanism for resource allocation, through the supply of rural public goods, the mode of innovation introduces market competition mechanisms and improves the supply efficiency of rural public goods. Farmers as beneficiaries of rural public goods, allowing them to participate in the decision-making of rural public goods can effectively optimize the supply and demand structure of rural public goods and improve supply performance. Therefore, during the transition period, the supply of rural public goods in China needs to reconstruct the supply model of "government-led, market-based, third-party promotion, and peasant household participation", and establish the institutional basis for the diversification of rural public goods supply subjects.

This paper proposes to introduce the PPP model to improve the existing model, mobilize village committees and villagers to participate in the treatment of rural household waste, and to exert the superiority and enthusiasm of each entity to achieve optimal allocation of rural resources.

This article proposes the following suggestions:

(1) Improve the waste disposal service system and build a cooperative interaction model between the government and the rural society. The village committee or the township government should plan and manage it in a unified manner.

(2) Strengthen rural household waste treatment capital investment, expand multiple financing channels, and establish a reasonable fund sharing mechanism.

(3) Improve the management and supervision system of rural household waste disposal to ensure the effective supply of infrastructure.

\section{References}

[1] Liu Ying, Wang Feng, Empirical Analysis of Disposal Methods of Household Wastes from Rural Households , Chinese Rural Economy,vol.15, pp. 88-96, 2012.

[2] He Pinjing, Discussion on treatment mode and technical route of domestic garbage in villages and towns, Journal of Agro-Environment Science, vol.33, pp.409-414.,2014.

[3] Li Guanjie, PPP model: The new choice of rural environmental infrastructure governance , Agricultural Economy, vol.12, pp.35-37, 2017.

[4] Fu Jingjing, Setbacks and Jurisprudence: Approaches to the Comprehensive Governance of Rural Environment under the Public-Private Partnership Model ,Journal of Yunnan University for Nationalities (Philosophy and Social Sciences Edition), vol.34, pp.86-91, 2017.

[5] Yan Hong and Tian Hongyu, The diversification of rural public goods supply subject: An analysis of a new political economy perspective, Rural economy,vol.05, pp.25-31, 2017.

[6] Li Guanjie, Research on the PPP Mode of Rural Environmental Infrastructure Governance in Shaanxi Province ,Legal System Expo, vol.08, pp.34-51, 2017. 